\title{
Failure of montelukast to reduce sputum eosinophilia in high-dose corticosteroid-dependent asthma
}

\author{
L. Jayaram, M. Duong, M.M.M. Pizzichini, E. Pizzichini, D. Kamada, A. Efthimiadis and F.E. Hargreave
}

ABSTRACT: Sputum eosinophilia is a sensitive predictor of benefit from corticosteroid treatment. Montelukast is a cysteinyl leukotriene antagonist, which also reduces sputum and blood eosinophils. The present study examined the possibility that montelukast has an added eosinophil-lowering effect in subjects with asthma who are corticosteroid responsive but relatively corticosteroid resistant.

A total of 14 clinically stable adults with asthma requiring minimum treatment with a high-dose inhaled steroid or prednisone, with baseline sputum eosinophilia $(\geqslant 5 \%)$, were randomised to receive 4 weeks of $10 \mathrm{mg}$ montelukast or placebo daily in a double-blind crossover trial. The primary outcome was the effect of treatment on the percentage of sputum eosinophils. Secondary outcomes were changes in the blood eosinophil count, symptoms, forced expiratory volume in one second, peak expiratory flow and the need for salbutamol.

The median (interquartile range, i.e. 75th-25th centile) for sputum eosinophils at baseline was $15.7 \%$ (22). The effect of adding montelukast was not significantly different from that of placebo, sputum eosinophils being $9.3 \%$ (18.9) after montelukast and $11.3 \%$ (22.8) after placebo. No difference was detected on secondary outcomes. No crossover interactions were observed.

In conclusion, the addition of montelukast to existing high-dose corticosteroid therapy in subjects with asthma with elevated sputum eosinophils does not provide additional attenuation of airway eosinophilia.

KEYWORDS: Montelukast, prednisone-dependent asthma, sputum cell counts

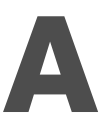
sthma is clinically defined by the presence of variable airflow limitation, but is also associated with airway inflammation [1]. The treatment of asthma is directed towards both of these components. Whilst airway inflammation is heterogeneous, sputum eosinophilia predicts improvement with corticosteroid treatment [2]. The improvement is associated with the reversal of sputum eosinophilia and improvement in airway responsiveness and airflow limitation. Sputum eosinophilia is also a sensitive marker of eosinophilic exacerbations of asthma and control of it reduces these [3-5]. Hence, it is reasonable to consider that control of airway eosinophilia should be an objective of the treatment of asthma.

In a minority of patients with asthma, high-dose corticosteroid is required to maintain optimum treatment. In these patients, a drug with an added anti-inflammatory effect might allow a reduction in the corticosteroid dose needed.
Another drug which lowers airway eosinophilia is montelukast, a cysteinyl leukotriene-receptor antagonist (LTRA). Cysteinyl leukotrienes promote bone marrow eosinophilopoiesis and eosinophil chemotaxis into the airways, increase the surface expression of adhesion molecules on eosinophils and blood vessels facilitating their transmigration through endothelial barriers, and prolong eosinophil survival by upregulating gene expression of mediating cytokines and chemokines, such as interleukin (IL)-5 and eotaxin [5-9]. Montelukast lowers sputum and blood eosinophils in steroid-naive asthma, and in asthma requiring lower doses of inhaled steroid [10-12]. Its effect in asthma requiring maintenance treatment with higher doses of inhaled steroid or prednisone has not been investigated. Prednisone treatment has been observed as having no effect on bronchoalveolar lavage (BAL) fluid eicosanoid levels [13]. The current authors hypothesised that montelukast would have an added eosinophillowering effect in these patients.

\section{AFFILIATIONS}

Airways Research Group, Firestone Institute for Respiratory Health, St. Joseph's Healthcare and McMaster University, Hamilton, ON, Canada.

CORRESPONDENCE

F.E. Hargreave

Firestone Institute for Respiratory Health

St. Joseph's Healthcare

50 Charlton Ave. E.

Hamilton, ON L8N 4A6

Canada

Fax: 19055216158

E-mail: hargreav@mcmaster.ca

Received:

January 212004

Accepted after revision:

September 142004

\section{SUPPORT STATEMENT}

The study was supported by a medical school grant from Merck Frost Inc. (Point Claire-Dorval, QC Canada). L. Jayaram was supported by a Fellowship from Boehringer Ingelheim Inc. (Mississauga, ON, Canada). F.E. Hargreave was supported by the Father Sean 0'Sullivan Research Centre. 
Therefore, the ability of montelukast to reduce sputum eosinophilia in patients with asthma, who required chronic treatment with prednisone or higher doses of inhaled steroid and in whom additional corticosteroid had been shown to abolish the eosinophilia, was examined. The study was placebo controlled, double-blind, randomised and crossover. The primary outcome was the change in the sputum eosinophil count after 4 weeks of treatment. Secondary outcomes were changes in the blood eosinophil count, symptoms, forced expiratory volume in one second (FEV1), peak expiratory flow (PEF) and the need for salbutamol.

\section{MATERIAL AND METHODS Subjects}

A total of 14 adults with asthma were recruited from 30 adults who were screened between February and December 1999 in the clinics of the Firestone Institute for Respiratory Health (Hamilton, ON, Canada; table 1). Asthma was defined by symptoms of episodic wheeze, chest tightness and dyspnoea, plus an improvement of $\geqslant 12 \%$ or $200 \mathrm{~mL}$ in FEV1 after $200 \mu \mathrm{g}$ salbutamol or a course of additional prednisone within the last year. All subjects had been monitored by sputum cell counts (in addition to symptoms and spirometry) to decide the minimum treatment to prevent frequent exacerbations. All subjects required treatment with daily high-dose inhaled steroid (budesonide $\geqslant 800 \mu \mathrm{g} ; \mathrm{n}=14$ ) or additional prednisone $(n=11)$ to optimise symptoms and spirometry. In this state, all but two had chronic airflow limitation (FEV1/vital capacity: $<70 \%$ predicted). Four subjects were ex-smokers of $\geqslant 10$ packyrs. None had any other evidence of chest disease, including emphysema (based on computerised tomography of the thorax and carbon dioxide gas transfer), reversible, or confounding causes for steroid insensitivity, or intolerance to nonsteroid anti-inflammatory drugs [14]. Those with an upper respiratory tract infection and those requiring antibiotics within 4 weeks of commencing the study were excluded. At entrance into the study, the subjects were clinically stable, but not necessarily ideally treated. Most had some daily symptoms (table 2) and an FEV1 below predicted and below their best value in the last year (table 1). The patients' corticosteroid dose had been unchanged for a minimum of 2 months. All subjects had sputum eosinophilia of $>5 \%$ (normal $<2 \%$ ), which had been reversed by previous increases in corticosteroid treatment. The study was approved by the hospital research ethics board and all subjects gave written informed consent.

\section{Study design}

The present study consisted of a randomised, double-blind, crossover study of two periods with four visits over 10 weeks and no intervening washout period. At the first visit, subjects' characteristics were documented and allergy skin tests carried out. The subjects began to record daily symptoms, medication use, and morning and evening PEF in a diary card, which was continued throughout the study. After a 2-week run-in period, baseline data (visit two) were collected, including symptom severity, spirometry, induced sputum cell counts, blood eosinophil count and liver function tests. Sputum and blood measurements were made blind to clinical details. The subjects were randomised to receive either montelukast $10 \mathrm{mg}$ before bed or placebo for 4 weeks. They then crossed over to receive the alternative medication for a further 4 weeks. The procedures performed at the second visit were repeated at the end of each treatment. A washout period was not included

\section{TABLE 1 Subject characteristics}

\begin{tabular}{|c|c|c|c|c|c|c|c|c|c|c|c|c|c|c|}
\hline \multirow{2}{*}{$\begin{array}{l}\text { Patient } \\
\text { No. }\end{array}$} & \multicolumn{8}{|c|}{ Subject characteristics } & \multicolumn{6}{|c|}{ Best value in last 12 months } \\
\hline & $\begin{array}{l}\text { Age } \\
\text { yrs }\end{array}$ & Sex & $\begin{array}{l}\text { Smoker } \\
\text { pack-yrs }\end{array}$ & Atopy & $P$ mg $\cdot \mathbf{d}^{-1}$ & $\operatorname{ICS} \mu \mathbf{g} \cdot \mathbf{d}^{-1}$ & LABA & $\begin{array}{l}\text { FEV } 1 \% \\
\text { pred } V_{1}\end{array}$ & $\begin{array}{c}\text { FEV } 1 \\
\% \text { pred }\end{array}$ & $\begin{array}{c}\text { FEV }_{1} / \mathbf{V C} \\
\%\end{array}$ & $\begin{array}{c}\text { FEV } 1 \\
\Delta S \mathrm{~mL}\end{array}$ & $\begin{array}{l}\text { FEV } 1 \\
\Delta S \%\end{array}$ & $\begin{array}{c}\text { FEV } 1 \\
\Delta P \text { mL }\end{array}$ & $\begin{array}{l}\text { FEV } 1 \\
\Delta P \%\end{array}$ \\
\hline 1 & 58 & $M$ & 20 & No & 9 & 1600 & No & 48 & 76 & 46 & 410 & 23 & 1230 & 55 \\
\hline 2 & 60 & $\mathrm{M}$ & 76 & Yes & 20 & 3200 & Yes & 47 & 100 & 60 & 270 & 12 & 230 & 10 \\
\hline 3 & 68 & $F$ & 0 & Yes & 7.5 & 1600 & Yes & 64 & 71 & 59 & 150 & 12 & 250 & 21 \\
\hline 4 & 67 & $M$ & 4 & Yes & 10 & 2400 & Yes & 50 & 68 & 65 & 220 & 25 & 320 & 30 \\
\hline 5 & 73 & $M$ & 0 & No & 4 & 800 & No & 38 & 64 & 59 & 330 & 24 & 370 & 27 \\
\hline 6 & 42 & $\mathrm{M}$ & 0 & Yes & 10 & 3200 & No & 66 & 71 & 55 & 150 & 6 & 880 & 53 \\
\hline 7 & 58 & $M$ & 1.6 & No & 10 & 1600 & No & 29 & 40 & 36 & 310 & 33 & 100 & 9 \\
\hline 8 & 45 & $\mathrm{~F}$ & 0 & Yes & 0 & 2400 & No & 75 & 92 & 78 & 0 & 0 & 640 & 48 \\
\hline 9 & 64 & $F$ & 10 & No & 12.5 & 1200 & Yes & 51 & 55 & 43 & 180 & 18 & 180 & 15 \\
\hline 10 & 74 & $M$ & 5 & Yes & 0 & 1600 & No & 54 & 79 & 66 & 480 & 23 & 530 & 21 \\
\hline 11 & 69 & $F$ & 10 & No & 12.5 & 1600 & Yes & 68 & 72 & 63 & 360 & 23 & ND & ND \\
\hline 12 & 72 & $\mathrm{~F}$ & 1 & Yes & 0 & 1600 & Yes & 72 & 86 & 68 & 280 & 11 & 490 & 16 \\
\hline 13 & 54 & $F$ & 0 & Yes & 5 & 1600 & Yes & 55 & 66 & 58 & 320 & 37 & 220 & 17 \\
\hline 14 & 52 & $M$ & 0 & Yes & 5 & 1600 & No & 89 & 111 & 77 & 380 & 18 & 1030 & 42 \\
\hline Mean \pm SD & $61.1 \pm 10.2$ & & & & $7.5 \pm 5.7$ & $1857.1 \pm 694.7$ & & $61.5 \pm 15.4$ & $75 \pm 18$ & $59.5 \pm 11.9$ & $274.3 \pm 125.2$ & $18.9 \pm 10$ & $487.9 \pm 342$ & $27.8 \pm 15.6$ \\
\hline
\end{tabular}

Atopy: $\geqslant 1$ positive $\left(\geqslant 3 \mathrm{~mm}\right.$ ) weal with allergy skin-prick tests; $\mathrm{P}$ : prednisone; ICS: inhaled corticosteroid (budesonide equivalent dose); LABA: long-acting $\beta_{2}$-agonist; FEV1: forced expiratory volume in one second; V1: visit one; VC: vital capacity; $\Delta$ S: change with salbutamol $200 \mu g ; \Delta P$ : change with added prednisone; M: male; F: female; ND: not done. 
TABLE 2 Inflammatory and clinical outcomes at baseline, with montelukast and placebo

\begin{tabular}{|c|c|c|c|c|}
\hline Inflammatory & Baseline & Montelukast & Placebo & p-value \\
\hline Sputum total cell count $10^{6}$ cells $\cdot g^{-1 \#}$ & $6.3(5.2)$ & $5.7(6.7)$ & $7.1(13.8)$ & 0.53 \\
\hline Eosinophils \%\# & $15.7(21)$ & $9.3(18.9)$ & $11.3(22.8)$ & 0.14 \\
\hline Neutrophils \% & $54.5 \pm 16.7$ & $42.8 \pm 25.8$ & $45.7 \pm 22.4$ & 0.21 \\
\hline Blood eosinophils $10^{9}$ cells $\cdot \mathrm{mL}^{-1}$ & $0.38 \pm 0.24$ & $0.35 \pm 0.25$ & $0.41 \pm 0.28$ & 0.12 \\
\hline \multicolumn{5}{|l|}{ Clinical } \\
\hline \multicolumn{5}{|l|}{ FEV $_{1}$} \\
\hline Postbronchodilator $\mathrm{L}$ & $1.96 \pm 0.80$ & $2.05 \pm 0.80$ & $1.98 \pm 0.76$ & 0.19 \\
\hline$\%$ & $63.2 \pm 17.3$ & $66.8 \pm 16.1$ & $64.7 \pm 17.3$ & 0.41 \\
\hline Morning PEF L. $\mathrm{min}^{-1}$ & $340 \pm 95$ & $339 \pm 101$ & $339 \pm 99$ & 0.90 \\
\hline Evening PEF L. $\min ^{-1}$ & $347 \pm 97$ & $348 \pm 96$ & $334 \pm 86$ & 0.70 \\
\hline \multicolumn{5}{|l|}{ Diurnal PEF variation } \\
\hline
\end{tabular}

Data are presented as mean \pm SD. The baseline is equivalent to the second visit. PEF: peak expiratory flow, calculated mean over the last 7 days. Diurnal PEF variation calculated as 1) amplitude \% mean=(maximum-minimum)/mean of last 7 days, and 2) lowest morning PEF \%=subject's personal best of last 7 days. The p-value was calculated by ANCOVA comparing montelukast to placebo with baseline as covariate. ${ }^{\#}$ : median (interquartile range); ${ }^{\bullet}$ : five worst, 35 best.

to ensure that the study was completed in a reasonable time to minimise any risk of a secular trend with time, which might result in a period-treatment interaction. In addition, the study design took into account that the comparison of montelukast and placebo would be made at the end of 4 weeks, when any carry-over effect should be negligible [15].

\section{Procedures}

Subject characteristics were documented with a structured questionnaire. Symptoms (shortness of breath, chest tightness, wheeze, cough and sputum) were recorded using a validated seven-point Likert scale, with a score of five being the worst and 35 the best [16]. Allergy skin tests were performed by the modified prick technique [17] with 14 common allergen extracts. Spirometry was performed with a Koko spirometer (PDS Instrumentation, Louisville, CO, USA), according to the American Thoracic Society specifications [18], before and $10 \mathrm{~min}$ after $200 \mu \mathrm{g}$ salbutamol was inhaled through an Aerochamber (Trudell Medical International, London, ON, Canada). The FEV1 was recorded as the best of three reproducible values (within a maximum change of $5 \%$ ). Reference values were taken from CRAPO et al. [19]. PEF was recorded as the best of three blows using a mini-Wright peak flow meter (Clement Clarke Inc., Mason, OH, USA). Diurnal variation of PEF was calculated using two methods. The first used the amplitude \% mean (maximum value minus the minimum value, divided by the mean) of the 7 days before each visit. The second method used the lowest morning PEF expressed as a percentage of personal best over the same period of time [20]. Assessment of compliance was by pill count and weighing of inhaled medication canisters at each visit. Compliance with regular treatment for each subject was also checked against prescription records at the patients' pharmacy.
Sputum was induced and processed as described by PIZZICHINI et al. [3]. Peripheral blood was examined for cell counts and serum bilirubin, aspartate transaminase (AST), alanine transaminase (ALT), and alkaline phosphatase.

\section{Statistical analysis}

Descriptive statistics were used to summarise the clinical characteristics of the subjects. Dependent variables with a nonGaussian distribution, including the primary outcome, were $\log$ transformed before analysis. Measurements are reported as mean \pm SD unless otherwise specified. Repeated measures of ANOVA were used to compare the main effect of montelukast with placebo in a model with factors for treatment, treatment sequence, and baseline measures as covariates [15]. This model was adjusted for the differential regression to the mean effects due to imbalance in baseline values. Significance was accepted at $\mathrm{p}<0.05$ (two-tailed).

A sample size of 14 subjects was calculated to provide an $80 \%$ power of detecting ( $\alpha=0.05$, two-tailed) with a $\geqslant 50 \%$ difference in the sputum eosinophil count between treatment groups [21]. This difference was considered to be clinically significant a priori.

\section{RESULTS}

All 14 subjects completed the study. Compliance was questionable in one subject (patient No. 13) based on the pharmacy prescription profile and pill count; data from this subject were excluded from subsequent analysis.

Montelukast had no significant effect on the sputum eosinophil count $(p=0.14)$ or other total and differential cell counts compared with placebo (table 2). The sputum eosinophil counts after 4 weeks with either treatment were similar regardless of the treatment sequence allocated, indicating 
no treatment or carry-over effect $(p=0.38)$. Similarly, no significant differences were seen with montelukast compared with placebo on blood eosinophil counts, symptom scores, FEV1 diurnal variation of PEF or need for salbutamol.

One subject (patient 5) developed drug-induced hepatitis after 4 weeks' treatment with montelukast. The cause was attributed to montelukast because there was no history of other causes; the patient's pre-treatment liver function tests and follow-up liver ultrasonography were normal, and the serum bilirubin, ALT, AST and alkaline phosphatase, which rose to $10 \mu \mathrm{mol} \cdot \mathrm{L}^{-1}, 326 \mathrm{U} \cdot \mathrm{L}^{-1}, 262 \mathrm{U} \cdot \mathrm{L}^{-1}$ and $318 \mathrm{U} \cdot \mathrm{L}^{-1}$, respectively, returned to normal within 3 days of stopping the montelukast treatment.

\section{DISCUSSION}

In the current study, the addition of montelukast $10 \mathrm{mg}$ daily for 4 weeks did not reduce sputum eosinophils, improve symptoms or airway function compared with placebo in subjects with asthma. The patients selected for the study had current sputum eosinophilia; they were corticosteroid responsive and the eosinophilia had been previously abolished by adequate corticosteroid treatment. However, the patients were relatively steroid resistant as indicated by the need for daily treatment with high-dose maintenance corticosteroid. The results may argue against montelukast having a steroid sparing effect in patients with these characteristics.

The lack of benefit is supported in a different study by the failure of montelukast to reduce elevated blood eosinophil counts in subjects needing treatment with moderate-to-high doses of inhaled steroid [21]. The result is contrary to the effect of montelukast in lowering sputum and blood eosinophils in subjects with asthma who were not being treated with inhaled steroids or being treated with low doses [10-12]. Hence, montelukast seems incapable of lowering eosinophils in subjects who are relatively corticosteroid resistant and need daily treatment with prednisone or higher doses of inhaled steroid.

The strength of the present study is that it has a randomised, controlled double-blind design. Possible weaknesses that need discussion include the dose and duration of montelukast treatment, the lack of a washout period between treatments in the crossover design, possible regression to the mean in sputum eosinophilia, and the power of the sample size to detect a difference between the two treatments. With respect to dose, it is possible that a higher dose of montelukast might have been more effective in the patients in the present study, just as previous treatment with higher doses of corticosteroid had been. This is a consideration for future study. However, against this possibility are the observations of ALtMAN et al. [22] who found, in a dose-ranging study in moderate-to-severe asthma (FEV1 59-62\% predicted), that montelukast $10 \mathrm{mg}$ daily, over 6 weeks, produced similar improvement to doses of 100 or $200 \mathrm{mg}$ in blood eosinophil counts, symptoms, FEV1 and PEF. With respect to duration of treatment, there has been no study in subjects needing higher doses of corticosteroid treatment. However, in those needing lower doses, montelukast reduces sputum eosinophils after 1 and 4 weeks of treatment $[10,23]$.
A washout period was omitted from the present study for reasons stated previously in the Methods section. The current authors do not believe that this is a weakness of the study, since montelukast binds reversibly to the leukotriene receptor, reaches steady state by day 2 and has a plasma terminal halflife of $5.3 \mathrm{~h}$ (up to $6.6 \mathrm{~h}$ in the elderly); this suggests that its clinical effects last, at most, for $33 \mathrm{~h}$ (five half-lives) [24]. Furthermore, several previous crossover trials examining the efficacy of adding montelukast to placebo in subjects on corticosteroids have omitted a washout period without evidence of carry-over interactions [25-27]. For example, a two-period, 16-week crossover trial, with a 2-week run-in phase, comparing the effect of adding montelukast or placebo to subjects with mild asthma already on fluticasone proprionate, found similar insignificant reductions in inflammatory cells on bronchial biopsy [27].

The subjects in the present study were selected to have sputum eosinophilia of $\geqslant 5 \%$ to provide a signal of response to treatment [28]. This could have resulted in a regression to the mean and contributed to the nonsignificant result. However, because of the crossover design, regression to the mean should occur equally with both treatments, allowing any genuine additional anti-inflammatory effect of montelukast to be detected. In addition, the statistical model used for the analysis adjusted for the differential regression to the mean effects due to imbalance in baseline values [29]. Finally, the lack of an eosinophil lowering effect of montelukast does not seem to be due to an underpowered study. A retrospective power analysis, using the data obtained in the current study, demonstrated that the trial had a $93 \%$ power to detect a $50 \%$ difference, and an $80 \%$ power to detect a $30 \%$ difference in sputum eosinophils between montelukast and placebo.

The results of the present study, therefore, do not support an added effect of montelukast on eosinophilic bronchitis in subjects with the characteristics investigated. Here, it is relevant to ask if sputum eosinophilia is important in the reversal of effects. On the one hand, there is evidence that sputum eosinophilia is a sensitive predictor of eosinophilic exacerbations of asthma [3-5]. It is abolished, in association with clinical improvement, by adequate steroid treatment [2, $30]$ and the control of it reduces exacerbations [5, 31]. On the other hand, it has been observed that i.v. humanised monoclonal anti-IL-5 antibody failed to prevent allergen-induced late asthmatic responses despite attenuation of blood and sputum eosinophilia [32]. Hence, while sputum eosinophils are an important marker of eosinophilic airway inflammation, the cell itself may be a bystander in the inflammatory response rather than an effector participant in it. It is possible that montelukast may exert a greater effect on the mediators of eosinophil maturation, differentiation and activation in the airway. It may also reduce other functionally relevant cells, such as mast cells, basophils and lymphocytes and noncellular components of airway inflammation, such as airway oedema, which are not primary outcomes of the present study.

As a secondary objective, the current authors also examined the possibility of a clinical benefit of montelukast. Here, the sample size or population studied could have contributed to the lack of effect. The subjects had mild symptoms and, in general, only a mild reduction in FEV1 from their best values. 
Half of the subjects were also being treated with a long-acting $\beta_{2}$-agonist, which may have produced maximal benefit with respect to bronchodilator reversibility. However, a higher dose of corticosteroid had produced clinical improvement (table 1). The current authors have also reported that in similar patients treated with a higher dose of prednisone for a week, symptoms improved and the FEV1 returned to previous best values [3]. Furthermore, a larger study of 100 subjects with moderate-tosevere asthma, of similar design, powered to detect a difference in symptoms score and mean change in PEF of $10-15 \mathrm{~L} \cdot \mathrm{min}^{-1}$, also failed to find a difference after treatment for 2 weeks [25].

The current authors conclude that the addition of $10 \mathrm{mg}$ montelukast daily for 4 weeks to existing high-dose corticosteroid therapy does not provide additional attenuation of airway eosinophilia. This argues against the possibility that this dose and duration of treatment will have a steroid-sparing effect in patients with this type of asthma.

\section{ACKNOWLEDGEMENTS}

The authors would like to thank the patients who participated in the study, and S. Carruthers and S. Weston (Airways Research Group, Firestone Institute for Respiratory Health, St. Joseph's Healthcare and McMaster University, Hamilton, ON, Canada) for performing the cell counts.

\section{REFERENCES}

1 Lemiere C, Bai T, Balter M, et al. Adult asthma consensus guidelines update 2003. Can Respir J 2004; Suppl. A, 9A-33A.

2 Pavord ID, Brightling CE, Wolkman G, et al. Noneosinophilic corticosteroid unresponsive asthma. Lancet 1999; 353: 2213-2214.

3 Pizzichini MMM, Pizzichini E, Clelland L, et al. Prednisone-dependent asthma: inflammatory indices in induced sputum. Eur Respir J 1999; 13: 15-21.

4 Leuppe JD, Salome CM, Jenkins CR, et al. Predictive markers of asthma exacerbation during stepwise dose reduction of inhaled corticosteroids. Am J Respir Crit Care Med 2001; 163: 406-412.

5 Pizzichini MMM, Jayaram L, Pizzichini E, et al. Does sputum cell counts alter asthma exacerbations? The LOMA study. Am J Respir Crit Care Med 2004; 169: Suppl. 7, A366.

6 Hamid Q, Tulic M, Liu M, Moqbel R. Inflammatory cells in asthma: mechanisms and implications for therapy. J Allergy Clin Inmmunol 2003; 111: Suppl. 1, S5-S17.

7 Braccioni F, Dorman SC, O'Byrne PM, et al. The effect of cysteinyl leukotrienes on the growth of eosinophil progenitors from peripheral blood and bone marrow of atopic subjects. J Allergy Clin Immunol 2002; 110: 96-101.

8 Fregonese L, Silvestri M, Sabatini F, Rossi G. Cysteinyl leukotrienes induce human eosinophil locomotion and adhesion molecule expression via a Cys-LT1 receptor-mediated mechanism. Clin Exp Allergy 2002; 32: 745-750.

9 Lee E, Roberston T, Smith J, Kilfeather S. Leukotriene receptor antagonists and synthesis inhibitors reverse survival in eosinophils of asthmatic individuals. Am J Respir Crit Care Med 2000; 161: 1881-1886.
10 Pizzichini E, Leff JA, Reiss TF, et al. Montelukast reduces airway eosinophilic inflammation in asthma: a randomised, controlled trial. Eur Respir J 1999; 14: 12-18.

11 Malmstrom K, Rodriguez-Gomez G, Guerra J, et al. Oral montelukast, inhaled beclomethasone, and placebo for chronic asthma. Ann Intern Med 1999; 16: 487-495.

12 Laviolette M, Malmstrom K, Lu S, et al. Montelukast added to inhaled beclomethasone in treatment of asthma. Am J Respir Crit Care Med 1999; 160: 1862-1868.

13 Dworski R, Fitzgerald GA, Oates JA, Sheller JR. Effect of oral prednisone on airway inflammatory mediators in atopic asthma. Am J Respir Crit Care Med 1994; 149: 953-959.

14 Barnes PJ, Woolcock AJ. Difficult asthma. Eur Respir J 1998; 12: 1209-1218.

15 Senn S. Cross-over trials in clinical research. 2nd Edn. London, John Wiley \& Sons Ltd, 2002; pp. 245-258.

16 Gibson PG, Wong BJO, Hepperle MJE, et al. A research method to induce and examine a mild exacerbation of asthma by withdrawal of inhaled corticosteroid. Clin Exp Allergy 1992; 22: 525-532.

17 Pepys J. Skin tests in diagnosis. In: Gell PGH, Coombs RRA, PJ Lachmann, eds. Clinical aspects of immunology. 3rd Edn. Oxford, Blackwell Scientific Publications, 1975; pp. 55-80.

18 American Thoracic Society. Standardization of spirometry. 1994 Update. Am Rev Respir Dis 1995; 152: 1107-1136.

19 Crapo RO, Morris AH, Gardner RM. Reference spirometric values using techniques and equipment that meets ATS recommendation. Am Rev Respir Dis 1981; 123: 659-694.

20 Reddel H, Jenkins C, Woolcock A. Diurnal variability: time to change asthma guidelines? BMJ 1999; 319: 45-47.

21 Tohda Y, Fujimura M, Taniguchi H, et al. Leukotriene receptor antagonist, montelukast, can reduce the need for inhaled steroid while maintaining the clinical stability of asthma subjects. Clin Exp Allergy 2002; 32: 1180-1186.

22 Altman L, Munk Z, Seltzer J, et al. A placebo controlled, dose-ranging study of montelukast, a cysteinyl leukotriene-receptor antagonist. J Allergy Clin Immunol 1998; 102: 50-56.

23 Minoguchi K, Kohno Y, Minoguchi H, et al. Reduction of eosinophilic inflammation in the airways of patients with asthma using montelukast. Chest 2002; 121: 732-738.

24 Zhao J, Rogers D, Holland S, et al. Pharmacokinetics and bioavailability of montelukast sodium (MK-0476) in healthy young and elderly volunteers. Biopharm Drug Dispos 1997; 18: 769-777.

25 Robinson DS, Campbell D, Barnes PJ. Addition of leukotrienes antagonists to therapy in chronic persistent asthma: a randomised double-blinded placebo-controlled trial. Lancet 2001; 357: 2007-2011.

26 Currie GP, Lee DK, Haggart K, Bates CE, Lipworth BJ. Effects of montelukast on surrogate inflammatory markers in corticosteroid treated patients with asthma. Am J Respir Crit Care Med 2003; 167: 1232-1238.

27 O'Sullivan S, Akveld M, Burke CM, Poulter L. Effect of the addition of montelukast to inhaled fluticasone proprionate 
on airway inflammation. Am J Respir Crit Care Med 2003; 167: 745-750.

28 Kips J, Inman MD, Jayaram L, et al. The use of induced sputum in clinical trials. Eur Respir J 2002; 20: Suppl. 37, 47s-50s.

29 Yudkin PL, Stratton IM. How to deal with regression to the mean intervention studies. Lancet 1996; 347: 241-243.

30 Brightling CE, Monteiro W, Ward R, et al. Sputum eosinophilia and short-term response to prednisolone in chronic obstructive pulmonary disease: a randomized controlled trial. Lancet 2000; 356: 1480-1485.

31 Green $\mathrm{RH}$, Brightling $\mathrm{CE}$, McKenna $\mathrm{S}$, et al. Asthma exacerbations and sputum eosinophil counts: a randomized controlled trial. Lancet 2002; 360: 1715-1721.

32 Leckie MJ, ten Brinke A, Khan J, et al. Effects of an interleukin-5 blocking monoclonal antibody on eosinophils, airway hyper-responsiveness, and the late asthmatic response. Lancet 2000; 356: 2144-2148. 